\title{
ANÁLISE FILOSÓFICA SOBRE O PRINCÍPIO DA DIGNIDADE HUMANA COMO UMA NOVA TEORIA DE JUSTIÇA
}

\author{
Cleide Aparecida Gomes Rodrigues Fermentão*
}

SUMÁRIO: Introdução; 2 Noções Filosóficas sobre Justiça; 3 AJustiça e a Igualdade; 4 AJustiça e o Direito a Liberdade; 50 Princípio da Dignidade Humana como uma Nova Teoria de Justiça; 6 Conclusões; Referências.

RESUMO: A análise da Justiça como valor essencial e a dignidade humana como uma nova teoria de justiça, é o que propõe o presente artigo. Para isso far-se-á uma pesquisa filosófica sobre as teorias da justiça defendidas por John Rawls, e por Serge-Christophe Kolm, e a análise da justiça como igualdade e liberdade. O vínculo essencial para a vida com liberdade e dignidade humana, se desenvolve entre o direito e os fatos sociais, sob a influência da vida social, que de forma dinâmica acrescenta a cada dia novos valores, e a pessoa humana é protegida pelo Princípio da dignidade humana em seus direitos personalíssimos, que lhe garante justiça. Dentre todos os valores que fincam a pessoa humana à vida, a justiça, a dignidade, e a liberdade se apresentam como necessários para nortear os pensamentos e proporcionar condições para que o homem se conheça, se estruture e tenha como tutela os seus valores interiores, e o direito como essencialidade. O princípio da dignidade humana, diante da crise dos valores morais, sociais e éticos. tem sido a garantia de justiça.

PALAVRAS-CHAVE: Justiça; igualdade; liberdade; dignidade humana.

\section{PHILOSOPHICAL ANALYSIS ON THE PRINCIPLE OF HUMAN DIGNITY AS A NEW THEORY OF JUSTICE}

ABSTRACT: The analysis of Justice as an essential value and Human Dignity as a new theory of justice is debated. A philosophical research on the theories of justice defended by John Rawls and on the analysis of justice as equality and freedom by Serge-Christophe Kolm is conducted. The basic link to a life of freedom and human dignity develops between rights and social facts, under the influence of social life, which dynamically adds new values daily. The human person is protected by the principle of human dignity in its personal rights that guarantee justice. Among the

Doutora em Direito das Relações Sociais pela Universidade Federal do Paraná (UFPR); Graduação e Mestrado em Direito Civil pela Universidade Estadual de Maringá (UEM), Maringá, PR, Brasil; Membro do Instituto dos Advogados do Estado do Paraná; do Instituto Brasileiro de Direito de Família (IBDFAM); Docente na graduação e no Programa de Pós-graduação em Ciências Jurídicas Mestrado do Centro Universitário de Maringá (UNICESUMAR), Maringá (PR), Brasil; Pesquisadora pelo ICETI; Advogada; E-mail: cleidefermentao@gmail. com 
values that foreground the human person to life, justice, dignity and freedom are necessary to direct ideas and provide conditions so that people may know and structure themselves, under the tutelage of interior values and law as an essential factor. In the wake of current crisis in moral, social and ethical values, justice has warranted the principle of human dignity.

KEY WORDS: Justice; Equality; Liberty; Human dignity.

\section{ANÁLISIS FILOSÓFICO DEL PRINCIPIO DE LA DIGNIDAD HUMANA COMO UNA NUEVA TEORÍA DE LA JUSTICIA}

RESUMEN: El análisis de la justicia como un valor esencial y la dignidad humana como una nueva teoría de la justicia es lo que propone este artículo. Por esta gran habrá una investigación filosófica en las teorías de la justicia defendidos por John Rawls, y Serge-Christophe Kolm, y el análisis de la justicia como igualdad y la libertad. El enlace vital para la vida con libertad y dignidad humana, se desarrolla entre la ley y los hechos sociales, bajo la influencia de la vida social, lo que añade dinámicamente cada día nuevos valores, y la persona humana está protegido por el principio de la dignidad humano en sus derechos personales, que garantiza la justicia. Entre todos los valores que se pegan a la persona humana a la vida, la justicia, la dignidad y la libertad se presenta como necesaria para guiar los pensamientos y proporcionar las condiciones para que el hombre se conoce, es estructurado y tiene la protección de sus valores internos, y el derecho a la esencialidad. El principio de la dignidad humana, a la crisis de los valores morales, sociales y éticos. Ha sido la garantía de justicia.

PALABRAS-CLAVE: Justicia; La igualdad; La libertad; La dignidad humana.

\section{INTRODUÇÃO}

A Justiça é um valor, e pode ser entendida como valor essencialmente humano e profundamente necessário para as realizações do convívio humano, pois nela mora a semente da igualdade. Para Platão é uma virtude suprema, para Aristóteles a igualdade e a proporcionalidade e para os juristas romanos, dar à cada um o que lhe pertence. Dentre todos os valores que fincam a pessoa humana à vida, a justiça, a dignidade, e a liberdade se apresentam como necessários para nortear os pensamentos e proporcionar condições para que o homem se conheça, se estruture e tenha como tutela os seus valores interiores, e o direito como essencialidade. 
$\mathrm{O}$ vínculo essencial para a vida com liberdade e dignidade humana, se desenvolve entre o direito e os fatos sociais, sob a influência da vida social, que de forma dinâmica acrescenta a cada dia novos valores, e o ser humano tem a tutela de seus direitos, para viver uma vida digna.

A presente pesquisa enfrentará o seguinte questionamento: o princípio da dignidade humana como fundamento de proteção à vida humana em suas necessidades vitais, pode ser pensado como uma nova teoria de justiça? é um novo conceito de justiça? A ideia de justiça pode ser um princípio garantidor da felicidade pessoal? Para fazer tal análise, a pesquisa se desdobrará em noções filosóficas sobre justiça: a justiça e a Igualdade, a justiça e o direito à liberdade, e, o princípio da dignidade humana como uma nova teoria de justiça. E, buscará respaldo nas lições de John Wals, Imanuel Kant, Serge-Christophe Kolm, Jean-Louis Bergel, Hans Kelsen, Ronald Dworkin, Norberto Bobbio, J.J.Rousseau, Voltaire, entre outros.

A igualdade e a liberdade podem ser consideradas como eixo central de justiça, e os seus princípios regulam as estruturas básicas da sociedade. Pensar em dignidade humana como teoria da justiça é lembrar que tal princípio protege a vida, a liberdade e a igualdade. Protege os valores morais que se transformam em normas, e os demais valores. Por isso, pensar em estabelecer o princípio da dignidade humana como uma teoria de justiça no direito contemporâneo, é reconhecer a sua importância filosófica e estrutural para o direito.

\section{NOÇÕES FILOSÓFICAS SOBRE JUSTIÇA}

Os valores interiores correspondem à essência da pessoa, neles estão a consciência humana e o senso de justiça que a potencializa em conformidade com a escala de valores da sociedade em que vive. Entre os valores interiores está a liberdade, a privacidade, a intimidade e a alma humana. Existem valores próprios do direito, que atribuem a este a função de realizar a justiça. Logo, a justiça é um valor jurídico.

Nas lições de John Rawls, "A justiça é a primeira virtude das instituições sociais, como a verdade o é dos sistemas de pensamento". ${ }^{01}$ Kelsen considera a

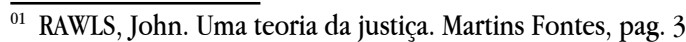


justiça "uma característica possível, porém não necessária, de uma ordem social". ${ }^{2}$ E indaga:

Mas o que significa ser uma ordem justa? Significa essa ordem regular o comportamento dos homens de modo a contentar a todos, e todos encontrarem sob ela felicidade. $\mathrm{O}$ anseio por justiça é o eterno anseio do homem por felicidade. Não podendo encontrá-la como indivíduo isolado, procura essa felicidade dentro da sociedade. Justiça é felicidade social, é a felicidade garantida por uma ordem social. ${ }^{03}$

O conceito de justiça passa por uma transformação radical: do sentido original da palavra (que implica o sentimento subjetivo que cada pessoa compreende para si mesma, de modo que a felicidade de um pode ser a infelicidade de outro) para uma categoria social: a felicidade da justiça. Tal transformação pode ser entendida como um princípio que garante a felicidade individual de todos. A idéia de justiça ser um princípio garantidor da felicidade pessoal, e este princípio ser garantido por meio da ordem social, é um novo conceito de justiça, que protege determinados interesses, ou seja, aqueles que são reconhecidos como dignos dessa proteção pela maioria dos subordinados a essa ordem ${ }^{04}$

A história da humanidade e de suas ideologias, assim como de suas tendências político-econômicas, tornou o Direito frágil, suscetível aos desmandos do poder político e econômico, deixando a Justiça fragilizada. Uma sociedade é considerada bem ordenada não apenas quando está planejada para promover o bem de seus membros, mas quando é também efetivamente regulada por uma concepção pública de justiça. ${ }^{05}$ A desigualdade social e o desrespeito aos valores pessoais e aos direitos personalíssimos tem violado a dignidade da pessoa humana, fazendo com que a dor da injustiça aflore.

A justiça é considerada por muitos a principal virtude, a fonte de todas as outras. A justiça é uma das noções mais prestigiadas do universo espiritual, e está longe de ser um valor exclusivamente revolucionário, ${ }^{06}$ ela está relacionada à felicidade pessoal. É obvio que não pode existir nenhuma ordem "justa", ou seja, uma ordem que proporcione felicidade a todos, caso se defina o conceito de felicidade

\footnotetext{
${ }^{02}$ KELSEN, Hans. O que é Justiça? a justiça, o direito e a política no espelho da ciência. São Paulo: Martins Fontes, 2001, p. 41.

03 Idem, p. 43.

04 Idem, p. 46.

05 RAWLS, John. Uma teoria da justiça. São Paulo: Martins Fontes, p. 05; 148.

${ }^{06}$ PERELMAN, Chaim. Ética e Direito. São Paulo: Martins Fontes, p. 7.
} 
em seu estado original, restrito, de felicidade individual, dando como significado de felicidade de um homem aquilo que ele considera que isso seja. ${ }^{07}$ Por sua própria definição, justiça é justificação, e, portanto, racionalidade no sentido normal do termo: por uma razão válida ou "justificado", indicando qual é a necessária forma geral de justiça: as igualdades ideais das liberdades ou dos meios ajustadas no interior de uma poliarquia moral estruturada.$^{08}$

Direito e Justiça são conceitos diferentes que às vezes andam em sintonia, outras não. Nem sempre caminham passo a passo. $O$ direito busca a justiça, tem nela a sua finalidade de existir e operar na vida social. O direito deve ser o meio, o veículo para a realização da justiça, e esta é o próprio objetivo do Direito. Justiça para ser plena tem na dignidade humana o seu mister, o seu espelho, o seu objetivo. Por isso, sempre que a dignidade for violada, tem-se imediatamente a injustiça.

$\mathrm{O}$ direito e a justiça estão relacionados aos valores morais que advém de "mores" ou costumes, onde o grupo social estabelece normas para proteger tais valores. Mas, não se pode esquecer que o grupo é composto por homens, e estes podem cometer injustiças enfraquecendo o próprio direito.

Voltaire ensina:

As leis não podem deixar de ressentir-se da fraqueza dos homens que as fizeram. Elas são variáveis como eles. Algumas das grandes nações foram ditadas pelos poderosos com o fim de esmagar os fracos. ${ }^{09}$

O Direito e a justiça precisam se aparelhar para fortalecimento do ordenamento jurídico, tendo como objetivo proteger a pessoa em suas garantias individuais, em sua liberdade e dignidade. Por maior que seja a fraqueza dos homens o direito precisa estar acima dela, podendo ser dito que aí está a importância do direito como sistema e ordenamento a proteger o homem.

Para Aristóteles,

O homem que obedece a lei e o homem equitativo serão ambos justos. O "justo", portanto, significa aquilo que é legal e equitativo, ou o que é igual ou equitativo, e o "injusto" significa aquilo que é ilegal e aquilo que é desigual ou não equitativo. ${ }^{10}$

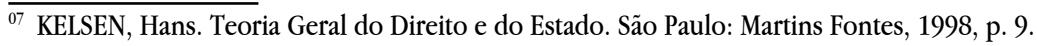

${ }^{08}$ KOLM, Serge-Christophe. Teorias modernas da justiça. São Paulo: Martins Fontes, 2000, p. 9.

${ }^{09}$ VOLTAIRE, O preço da justiça. São Paulo: Martins Fontes, 2001, p. 7, 8.

${ }^{10}$ ARISTÓTELES, Ética a Nicômaco. 3. ed. Tradução Edson Bini. Bauru, SP: Edipro, 2009, p. 146.
} 
A "injustiça" é demonstrada nos atos dos homens que agem de forma errada, e esses atos errados mostram deficiência moral e não significam atos gananciosos, pois o ganancioso não mostra vícios, mas sim revela maldade e injustiça. ${ }^{11}$ Hans Kelsen considera a justiça "uma característica possível, porém não necessária, de uma ordem social". E indaga: "mas o que significa ser uma ordem justa? Significa essa ordem regular o comportamento dos homens de modo a contentar a todos, e todos encontrarem sob ela a felicidade. $\mathrm{O}$ anseio por justiça é o eterno anseio do homem por felicidade. Não podendo encontrá-la como indivíduo isolado, procura essa felicidade dentro da sociedade. Justiça é felicidade social, é a felicidade garantida por uma ordem social" 12

Ao se fazer uma análise sobre "A teoria da justiça de John Ralws", apresentada pelo mesmo em sua obra "Uma teoria da justiça", constata-se a sua importância como valor jurídico no século XX. A ideia foi de "elaborar uma teoria da justiça que fosse uma alternativa para essas doutrinas que há muito tempo dominam a tradição filosófica - a utilitária e a intuicionista". ${ }^{13} \mathrm{E}$ explica sobre a doutrina distributiva como princípio da justiça social:

Exige-se um conjunto de princípios para escolher entre várias formas de ordenação social que determinam essa divisão de vantagens e para selar um acordo sobre as partes distributivas adequadas. Esses princípios são os princípios da justiça social: eles fornecem um modo de atribuir direitos e deveres nas instituições básicas da sociedade e definem a distribuição apropriada dos benefícios e encargos da cooperação social. ${ }^{14}$

A teoria da justiça para Serg Christophe Kolm, "é racionalidade aplicada à questão da justiça, e a justiça é o resultado necessário dessa aplicação, [...] dizem respeito, fundamentalmente às liberdades e igualdades, bem como à estrutura geral da justiça". ${ }^{15}$

Voltaire questiona:

quem nos deu o sentimento do justo e do injusto? Foi Deus, que nos deu um cérebro e um coração. Mas em que momento nossa razão

\footnotetext{
${ }^{11}$ Idem, p. 148.

${ }^{12}$ KELSEN Hans. O que é justiça?: a justiça, o direito e a política no espelho da ciência. São Paulo: Martins Fontes, 2001, p. 2.

${ }^{13}$ RAWLS, John. Uma Teoria da Justiça. São Paulo: Martins Fontes, 2000, p. 3.

${ }^{14}$ Idem p. 5.

${ }^{15}$ KOLM, Serge-Christophe. Teorias modernas da justiça. São Paulo: Martins Fontes, 2000, p. 5.
} 
nos ensina que há vício e há virtude? Quando nos ensina que dois e dois são quatro. Não há conhecimento inato, pela mesma razão porque não há árvore que contenha folhas e frutos ao sair da terra. ${ }^{16}$

O direito precisa estar relacionado ao sistema de valores reconhecido de determinado grupo social, esse sistema pode diferir, e de fato, difere de lugar para lugar e de período para período. O direito deverá estar de acordo com esses valores, e deve visar sempre a justiça. ${ }^{17}$

Os valores sociais correspondem a tudo que tem sentido, significado, apreço, estima, para determinado grupo. Cada pessoa humana possui em seu interior valores e princípios, que a norteiam na eterna construção de seu espírito, conduzindo-a a novos comportamentos. Verdadeira construção humana a cada dia. E, esses valores individuais com o passar do tempo se transformam em valores coletivos, momento em que o direito precisa vir em proteção a tais valores. Valores coletivos ou valores sociais visam a justiça.

Segundo Heráclito de Éfeso (540-480 a. C), tudo existe em constante mudança, e o conflito é o pai e o rei de todas as coisas. Para ele vida ou morte, sono ou vigília, juventude ou velhice são realidades que se transformam umas nas outras. Em Fragmento 91, disse: "um homem não toma banho duas vezes no mesmo rio. Por quê? Porque na segunda vez não será o mesmo homem e nem se estará banhando no mesmo rio, ambas terão mudado".

Os gregos achavam a concepção de Heráclito abstrata, entendendo que se os seres se transformam, deixam de ser o que eram. Para Parmênides, a essência profunda do ser era "imutável", e que o movimento ou a mudança era um fenômeno de superfície ou seja, da metafísica. Porém, é na construção diária que os valores se enriquecem e passam a serem valores coletivos, e como tais, o direito precisa protegê-los.

A análise axiológica de determinada sociedade se faz preciso em razão de que o valor moral é em si mesmo a própria justiça. Se todos os propósitos morais da vida humana são classificados como "o bem", então a ideia de justiça é um "bem" que a moralidade coloca diante da humanidade. ${ }^{18}$

Para Dennis Lloyd

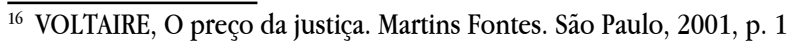

${ }^{17}$ DENNIS LLOYD, Barom. A ideia de lei. São Paulo: Martins Fontes, 2000, p.137.

${ }^{18}$ Idem p. 138.
} 
Um determinado "bem pode funcionar ou como um meio ou como um fim em si mesmo. [...] o que é o bem supremo é uma questão de escolha e não de demonstração, e poderíamos, se quiséssemos, colocar a própria justiça nesse pináculo. [...] alguns juristas e mesmo alguns notáveis filósofos, como Platão, colocaram a justiça no ápice do mundo moral. ${ }^{19}$

A análise da teoria de justiça de John Rawls por Donald Dworkin, lembra que tal teoria concebe que um grupo de homens e mulheres que se reúnem para constituir um contrato social, com gostos, talentos, ambições e conviç̧ões comuns, são racionais, e agem em seu próprio interesse, estes irão escolher seus princípios de justiça. Tais princípios seriam ter a mais ampla liberdade política, e igual liberdade para todos, e, que as desigualdades em termos de poder, riqueza, renda e outros recursos não devem existir, a menos que favoreçam o benefício dos membros em pior situação na sociedade..$^{20}$ John Rawls combatia em sua teoria de justiça a desigualdade social.

Aristóteles trata da justiça política, apresentando uma diferenciação entre a justiça natural e a justiça legal, que juntas formam a justiça política, dizendo: "Da justiça política, uma parte é natural e outra parte legal" ${ }^{21}$ Para Aristóteles a justiça natural é a parte da justiça política que é consensual, isto é, que tem validade em todos os lugares independentemente do juízo de valor humano, e a justiça legal é aquela que inicialmente podia ser cumprida de um jeito ou de outro, mas se impõe ao ser estabelecida por lei. ${ }^{22}$

Para a Justiça platônica, o microcosmo do homem justo é um reflexo do padrão de sociedade justa. Platão procurou chegar ao significado de justiça descrevendo o que poderia ser uma sociedade justa ou ideal. Será justa por se harmonizar com a sua ideia de justiça. Ele pensa que a justiça se aplica tanto para objetos quanto a pessoas, e justiça significa harmonizar-se, ajustar-se a essa esfera. ${ }^{23}$

A justiça como equidade é uma teoria de justiça que generaliza e leva a um nível mais alto de abstração. A justiça é a primeira virtude das instituições sociais. Cada pessoa possui uma inviolabilidade fundada na justiça, portanto, numa sociedade justa as liberdades da cidadania são consideradas invioláveis, Eis a primazia da justiça. ${ }^{24}$

\footnotetext{
${ }^{19}$ Idem p.139.

${ }^{20}$ DWORKIN Ronald. Levando os direitos a sério. São Paulo: Martins Fontes, 2002, p. 235.

${ }^{21}$ ARISTÓTELES. Ética a Nicômaco. São Paulo: Nova cultural, 1987, p. 91. Antonio Fabris Editor, 2002, p.62.

${ }^{22}$ PILON, Almir José. Liberdade e justiça: uma introdução à filosofia do direito em Kant e Rawls Sérgio

23 DENNIS LLOYD, Baron. A ideia de lei. São Paulo: Martins Fontes, 2000, p. 140.

${ }^{24}$ RAWLS, John. Uma teoria da justiça. São Paulo: Martins Fontes, 2002, p. 4.
} 


\section{A JUSTIÇA E A IGUALDADE}

O direito de cada homem de ser tratado com igualdade a despeito de sua pessoa, seu caráter ou seus gostos é reforçado pelo fato de que ninguém mais pode garantir-se numa posição melhor em virtude de ser diferente. Pode-se dizer que os indivíduos têm direito à igual consideração e ao igual respeito. ${ }^{25}$

A concepção de Justiça pode variar de época para época. Para os gregos está justiça estava consubstanciada na ideia de desigualdade, uma vez que a própria ausência de igualdade natural entre os seres humanos exigia tratamento diferente, em tempos modernos a opinião mudou para entender que a igualdade passou a ser considerada como a própria essência da justiça. ${ }^{26}$

A justiça formal requer igualdade de tratamento de acordo com as classificações estabelecidas pelas leis. Nenhum princípio puramente formal de tratamento de iguais como iguais bastará. As pessoas não nascem iguais fisicamente, mentalmente ou em outros aspectos, de modo que a classificação de igualdade entre seres humanos é uma simples formalidade. ${ }^{27}$

Para Chaim Perelman, a noção de justiça formal está vinculada à igualdade, como o substrato comum à concepção de justiça. A igualdade está fundamentada em valores, e cita como exemplo a riqueza e a beleza, E, estabelece como regra de justiça, a igualdade formal, por entender que "ser justo é tratar da mesma forma os seres que são iguais em certo ponto de vista, que possuem uma mesma característica, a única que se deve levar em conta na administração da justiça. Qualifiquemos essa característica de essencial." 28

A justiça formal ou abstrata, é, um princípio de ação segundo o qual os seres de uma mesma categoria essencial devem ser tratados da mesma forma ${ }^{29}$, A justiça é formal porque não determina as categorias que são essenciais para a aplicação da justiça. Ela permite que surjam as divergências no momento de passar de uma fórmula comum de justiça concreta para fórmulas diferentes de justiça. O desacordo nasce no momento em que se trata em determinar as características essenciais para a aplicação de justiça." ${ }^{30}$

\footnotetext{
${ }^{25}$ DWORKIN, Ronald. Levando os direitos a sério. Martins Fontes, São Paulo, 2002, p.278-279

${ }^{26}$ DENNIS LLOYD, Baron. A ideia de lei. Martins Fontes, São Paulo, 2000, p.141

${ }^{27}$ Ibidem, 2000, p. 142

${ }^{28}$ PERELMAN, Chäm. Ética e Direito. São Paulo: Martins Fontes, 2000, p. 18-19

${ }^{29}$ Ibidem, 2000, p. 19.

${ }^{30}$ Ibidem, p. 19.
} 
Nas lições de John Rawls,

Minha esperança é a de que a justiça como equidade pareça razoável e útil, mesmo que não seja totalmente convincente, para uma grande gama de orientações políticas ponderadas, e portanto, expresse uma parte essencial do núcleo comum da tradição democrática. ${ }^{31}$

A justiça é a esperança que todo homem traz em sua essência, sendo necessária para que este se realize. A justiça é ideia de virtude suprema, de equidade, de felicidade, de igualdade e de liberdade, verdadeira justiça social. A justiça social é a estrutura básica da sociedade, e a distribuição de direitos e deveres fundamentais, e determinam a divisão de vantagens. ${ }^{32}$

A Justiça social está relacionada à igualdade entre todas as pessoas. Cada pessoa deve ter um direito igual ao mais abrangente sistema de liberdades básicas iguais que seja compatível com um sistema semelhante de liberdades para as outras. E, as desigualdades sociais e econômicas devem ser ordenadas de tal modo que sejam ao mesmo tempo: consideradas como vantajosas para todos dentro dos limites do razoável, e vinculadas a posições e cargos acessíveis a todos. Tais princípios estruturam a sociedade como valores sociais. ${ }^{[33}$

A teoria da justiça como igualdade advém de Aristóteles, para garantir a igualdade, seja nas relações entre os indivíduos, chamada de justiça comutativa, seja nas relações entre o Estado e os indivíduos, chamada de justiça distributiva. $\mathrm{O}$ direito é o remédio para as disparidades entre os homens, sejam as desigualdades naturais como as desigualdades sociais.

\section{Segundo Norberto Bobbio}

Um ordenamento jurídico não pode ser considerado justo se não protege os fracos dos fortes, os pobres dos ricos, se não estabelece com as próprias regras uma medida ou uma série de medidas com as quais seja impedida a prevaricação e todos os membros de uma sociedade recebam igual tratamento. ${ }^{34}$

A teoria de justiça substancial ou por igualdade, trata iguais como iguais. A lei só pode ser considerada lei se for aplicada a todas as pessoas ou situações por ela abrangidas. Isso é justiça. ${ }^{35} \mathrm{~A}$ justiça como equidade defendida por John Rawals, "os

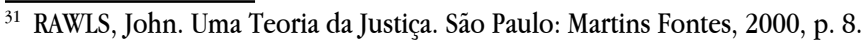

${ }^{32}$ RAWLS, John. Uma Teoria da Justiça. São Paulo: Martins Fontes, 2000, p. 10

${ }^{33}$ Ibidem, 2000, p. 64

${ }^{34}$ BOBBIO, Norberto. Direito e Estado no pensamento de Emanuel Kant. São Paulo; Mandarim, 2000, p. 117.

${ }^{35}$ DENNIS LLOYD. A ideia de lei. São Paulo: Martins Fontes, 2000, p. 147.
} 
cidadãos estão envolvidos na cooperação social, e portanto são plenamente capazes de fazer isso durante toda a vida". ${ }^{36}$

As pessoas livres e iguais são descritas como detentoras de duas faculdades morais: a capacidade de ter um senso de justiça, compreender e aplicar os princípios de justiça, e a capacidade de formar uma concepção do bem, uma concepção do que considera uma vida digna a ser vivida. ${ }^{37}$

As desigualdades sociais ferem a dignidade humana, isso porque cada pessoa deve ter um direito igual ao mais abrangente sistema de liberdades básicas, $\mathrm{e}$, as desigualdades sociais e econômicas devem ser ordenadas para que sejam consideradas como vantajosas para todos e vinculadas a posição e cargos aceitáveis a todos. ${ }^{38}$

Segundo J.J.Rosseau, há duas espécies de desigualdades na espécie humana:

Uma, a que chamo de natural ou física, por ser estabelecida pela natureza, e que consiste na diferença de idades, de saúde, das forças do corpo e das qualidades do espírito ou da alma; a outra, a que se pode chamar desigualdade moral ou política, por depender de uma espécie de convenção a ser estabelecida, ou pelo menos autorizada, pelo consentimento dos homens. Esta consiste nos diferentes privilégios que alguns usufruem em prejuízo dos outros, como serem mais ricos, mais reverenciados e mais poderosos do que lês, ou mesmo em se fazerem obedecer por eles. ${ }^{39}$

Rosseau trata das desigualdades de condições e das fortunas, da diversidade das paixões e dos talentos, das artes inúteis, das artes perniciosas, e das ciências frívolas sairiam multidões de preconceitos. Instalada a desordem e fruto das revoluções, o despotismo devorou tudo que tivesse percebido de bom e de sadio em todas as partes do Estado, pisando nas leis e o povo vivendo sob ruínas. ${ }^{40}$

As desigualdades sociais representam as diferenças de possibilidades: de vida digna, de ter voz e ser ouvido, de existência de preconceitos e segregação social, um grito sufocado por justiça, um constrangimento que faz rasgar a alma da pessoa que se sente injustiçada. Como pensar em justiça diante do despotismo social, da fome, da sede, e de todas as necessidades humanas.

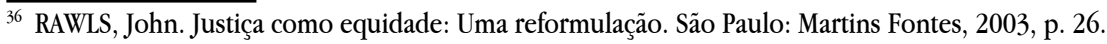

${ }^{37}$ RAWLS, John. Justiça como equidade: Uma reformulação. São Paulo: Martins Fontes, 2003, p. 26.

${ }^{38}$ RAWLS, John. Uma teoria da Justiça. São Paulo: Martins Fontes, 1997, p. 64.

${ }^{39}$ ROSSEAU, J. J. Discurso sobre a origem e os fundamentos da desigualdade entre os homens. São Paulo: Martins Fontes, 1999, p.160.

${ }^{40}$ Ibidem, p. 239.
} 


\section{A JUSTIÇA E O DIREITO À LIBERDADE}

Ao se analisar a justiça e a liberdade, esta é o bem jurídico tutelado, que pode ser entendido como a prerrogativa que tem a pessoa de desenvolver suas atividades no mundo das relações, com a proteção do Estado, garantidas pelo Ordenamento Jurídico.

O Estado tem a obrigação de proteger o direito à liberdade, como direito personalíssimo da pessoa humana, considerada como essencial à personalidade humana. São essenciais à pessoa: a sua personalidade, o direito de locomoção, de pensamento e de expressão, de participação em cultos religiosos e de comunicação em geral. A essência de tais direitos personalíssimos é possibilitar à pessoa humana viver com dignidade e justiça.

$\mathrm{O}$ direito à liberdade, como direito da personalidade, consiste em estabelecer ao ser humano por meio da proteção do Estado, condições para que este direcione suas energias, de acordo com a sua vontade, para alcançar os seus objetivos, quer no plano pessoal, quer no plano negocial, quer espiritual. ${ }^{41}$

O vocábulo latino líber, do qual deriva "livre", teve a princípio o sentido de "pessoa na qual o espírito de procriação se acha naturalmente ativo", donde a possibilidade de se chamar líber ao jovem, quando, ao alcançar a maturidade sexual, se incorpora como homem capaz de assumir responsabilidades. Recebe, então, a toga virilis ou toga libera. Nesse sentido, o homem livre é aquele que não é escravo. ${ }^{42}$

Ser livre é estar disponível para fazer algo por si mesmo. Nesse sentido, a liberdade se afigura com a possibilidade de decidir e, ao decidir, auto determinar-se. A liberdade pressupõe responsabilidades do indivíduo para consigo mesmo e ante a comunidade. Os romanos assim a definiam: A liberdade é a faculdade natural de fazer cada um o que deseja, se a violência ou o direito lhe não proíbe. ${ }^{43}$

Um homem livre é aquele que, naquelas coisas que graças a sua força e engenho é capaz de fazer, não sofre nenhum impedimento. É o pleno exercício da liberdade, não bastando apenas a vontade, a necessidade, mas também a possibilidade de exercer tal liberdade. Liberdade corresponde às ações que os homens voluntariamente praticam, dado que derivam de sua vontade, é o que ensina Márcio Sotelo Felipe:

${ }^{41}$ FERMENTÃO. Cleide Aparecida Gomes Rodrigues. Direito a liberdade: por um paradigma de essencialidade que tutele o direito personalíssimo da liberdade. Curitiba: Juruá, 2009.

${ }^{42}$ SANTOS, Maria Celeste Cordeiro Leite. Transplante de órgãos e eutanásia. São Paulo: Revista dos Tribunais, 2001, p. 5.

${ }^{43}$ DE PLÁCIDO E SILVA, op. cit., p.84. 
[...] um homem livre é aquele que, naquelas coisas que graças a sua força e engenho é capaz de fazer, não é impedido de fazer o que tem vontade de fazer...Tal como as águas, não tinham apenas a liberdade, mas também a necessidade de descer pelo canal, assim também as ações que os homens voluntariamente praticam, dado que derivam de sua vontade, derivam da liberdade. ${ }^{44}$

A igualdade pode ser considerada como valor supremo de uma convivência ordenada, feliz e civilizada em sociedade. A igualdade frequentemente é acoplada com a liberdade. Liberdade e igualdade tem na linguagem política um significado positivo. ${ }^{45} \mathrm{O}$ homem ao ter a sua liberdade tolhida sem que tenha cometido qualquer ato contrário à lei, sem que tenha praticado qualquer ato que turbe a ordem pública e que fira a sociedade e seus valores, pelo fato de não poder ser desprovido de sua liberdade, sente o peso da injustiça sobre si.

Kant entende como ação justa aquela que a liberdade do arbítrio de um pode continuar com a liberdade de qualquer outro, segundo uma lei universal. Ele se preocupa em estabelecer o critério para distinguir uma ação justa de uma injusta ${ }^{46}$.

A justiça é uma qualidade ou atributo de uma conduta humana específica, que consiste no tratamento dado a outros homens. O juízo segundo o qual uma conduta é justa ou injusta representa uma apreciação, uma valoração da conduta. A conduta é confrontada com uma norma de justiça que determina um dever ser, conduta valiosa que tem um valor de justiça positivo. ${ }^{47}$

\section{O PRINCÍPIO DA DIGNIDADE HUMANA COMO UMA NOVA TEORIA DE JUSTIÇA}

O Princípio da dignidade humana confere à pessoa humana por meio da Constituição Federal de 1988 o Direito de desenvolver-se física e psiquicamente, com respeito à vida e à liberdade. A sua origem e a sua travessia na história advém da Declaração dos Direitos do homem e do cidadão, em 1789 após a revolução francesa; da Declaração Universal dos Direitos do homem (direitos humanos), em 1948, após a 2a . Guerra Mundial chegando à Constituição Federal pátria de 1988.

\footnotetext{
${ }^{44}$ FELIPPE, Mário Sotelo. Razão jurídica e dignidade humana. São Paulo: Max Limonad, 1996, p. 48.

${ }^{45}$ BOBBIO, Norberto. Igualdade e liberdade. Rio de Janeiro:Ediouro,2002, p.11.

${ }^{46}$ BOBBIO, Norberto. Direito e Estado no pensamento de Emanuel Kant. São Paulo. Mandarim, 2000. p.116.

${ }^{47}$ KELSEN, Hans. O problema da Justiça. São Paulo: Martins Fontes,1998, p. 4.
} 
O constituinte de 1988 consagrou nos Arts. $1^{\circ}$ e $3^{\circ}$ da Constituição Federal de 1988, a dignidade do homem como valor primordial, propiciando unidade e coesão ao texto, de molde a servir de diretriz para a interpretação de todas as normas que o constituem. Foram elencados nos primeiros capítulos da $\mathrm{CF} / 88$, inúmeros direitos e garantias individuais, e lhes foi outorgado o patamar de CLÁUSULAS PÉTREAS, conforme o art. $60, \S 4^{\mathrm{O}}$, inciso IV, priorizando assim, os direitos humanos.

No art. $5^{\circ}$, parágrafo $2^{\circ}$ a Constituição Federal estabelece:

Os direitos e garantias expressos nesta constituição não excluem outros decorrentes do regime e dos princípios por ela adotados, ou dos tratados internacionais de que a República Federativa do Brasil seja parte.

Verifica-se com isso, a possibilidade da existência de outros direitos e garantias fundamentais inseridos ao longo de todo o texto constitucional, como também o fato de os direitos e garantias decorrentes de tratados internacionais receberem o mesmo tratamento dos direitos fundamentais, e passarem a ter aplicabilidade imediata no direito interno.

Diversas são as palavras usadas para aludir à existência do Direito: vigência, eficácia, observância, faticidade e efetividade do Direito. Validez e vigência do Direito, corresponde a existência do Direito, as outras palavras são vocábulos sinônimos. A eficácia é o fato de que a norma é efetivamente aplicada e seguida, e pertence à ordem do ser, dos fatos. Parece contraditório falar em eficácia de princípios quando inúmeras regras pairam no ordenamento jurídico sem regulamentação. Mas a verdade que se deve buscar é a eficácia das regras e princípios de forma concomitante e complementar ou não faria sentido afirmar que os princípios também são normas jurídicas.

Ressalte-se que os princípios exigem a realização de algo e embora não contenham determinações proibitivas ou permissivas, como ocorre com as regras jurídicas, impõem a otimização de um direito ou de um bem jurídico, tendo em conta a reserva do possível, fática ou jurídica. ${ }^{48}$

A dignidade pode ser distinguida em humana ou ontológica e ética. A dignidade ontológica é uma qualidade inseparável do ser humano. Esta noção remete à ideia de incomunicabilidade, de unicidade, de impossibilidade de reduzir o homem a um simples número. A dignidade ontológica é o valor que se descobre

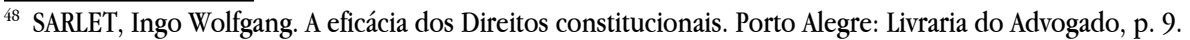


no homem bastando-lhe o fato de existir. Nesse sentido, todo homem, ainda que seja o pior dos criminosos, é um ser digno, e, portanto, não pode ser submetido a tratamentos degradantes, como a tortura ou outros. A dignidade ontológica é a natureza do ser humano como ser. $\mathrm{O}$ homem ao ser concebido adquire uma natureza comum que é inerente a todos, e, de forma especialíssima e particular, a sua própria natureza, logo, é ser digno, tendo virtude e honra como qualidade moral, e como tal deve ser visto como único, e respeitado como toda pessoa humana. ${ }^{49}$

A dignidade ética refere-se às obras praticadas pelas pessoas. Essa dignidade é o fruto de uma vida de acordo com a prática do bem, e não é praticado por todos do mesmo modo. Trata-se de uma dignidade construída por cada pessoa, por meio do exercício da liberdade. ${ }^{50}$

O princípio da dignidade da pessoa humana demarca o campo que foi denominado como "padrão mínimo na esfera dos direitos sociais", o que demonstra que a falta de condições materiais mínimas ao homem prejudica o próprio exercício da liberdade, retira da pessoa o seu desenvolvimento físico e psíquico, gerando a injustiça.

As agressões contra a dignidade atentam contra a própria humanidade do indivíduo, cabendo ao Estado não apenas coibi-las, mas proteger ativamente a vida humana, sendo esta a própria razão de ser do Estado, eis a importância da eficácia do Princípio da dignidade humana para a justiça.

Uma importante forma de caracterizar um direito como fundamental está em sua contribuição para a dignificação do homem, que se projeta na liberdade individual, no convívio social e em todas as esferas possíveis de alcançar a plenitude do desenvolvimento humano, daí porque os direitos sociais são fundamentais, atingindo também as pessoas na produção e potencialização de sua personalidade ${ }^{51}$.

Nas lições de Ingo Wolganf Sarlet,

A vida, a dignidade da pessoa humana, as liberdades mais elementares continuam sendo espezinhadas, mesmo que disponhamos, ao menos no direito pátrio, de todo um arcabouço de instrumentos jurídico-processuais e garantias constitucionais. O problema da efetividade é, portanto, algo comum a todos os direitos de todas as dimensões.52

\footnotetext{
${ }^{49}$ por qué es particularmente importante hoy en dia reflexionar sobre la noción de persona, planteándose dos preguntas, una ontológica y la otra ética: qué es la persona? cual es su valor? (ANDORNO, Roberto. Bioética y dignidad de la persona. p. 53)

${ }^{50} \mathrm{Cf}$. ANDORNO, Roberto. Bioética Y dignidad de la persona. p. 57.

${ }^{51}$ SARLET, Ingo Wolfgang. A eficácia dos Direitos constitucionais, p. 10

${ }^{52}$ Ibidem
} 
A dignidade humana está constitucionalizada como Direito fundamental na Constituição Federal de 1988, no Artigo $1^{\circ}$, III, como Princípio Constitucional, e pode ser considerada como uma nova teoria de justiça. E, encontra-se no epicentro da ordem jurídica brasileira tendo em vista que concebe a valorização da pessoa humana como sendo razão fundamental para a estrutura de organização do Estado e para o Direito. O legislador constituinte elevou à categoria de princípio fundamental. ${ }^{53}$ Porém, mesmo com a existência das normas, a vida e a liberdade humana estão esmagadas por um sistema injusto, verdadeira ineficácia das normas existentes.

A positividade do Direito não se confunde com sua vigência nem com sua eficácia. É mais que vigência e eficácia porque existem três modalidades de direito positivo: o dotado atualmente de vigência; o que já a perdeu; e o que está em vias de obtê-la..$^{54}$ As normas constitucionais possuem eficácia e irradiam efeitos jurídicos. A eficácia de certas normas não se manifesta em sua plenitude, sendo necessária a emissão de uma norma jurídica ordinária ou complementar executória.

O princípio da dignidade humana protege a vida, a liberdade, todos os direitos personalíssimos, e protegerá direitos futuros, como alicerce do Direito. Está vigente, e pode ser reconhecido como uma teoria de justiça diante da sua importância para tutelar novos direitos, sendo portanto uma bandeira de justiça.

Dignidade na definição de Kant,

Tudo tem ou bem um preço, ou bem uma dignidade. Podemos substituir o que tem um preço por seu equivalente. Em contrapartida, o que não tem preço, e, pois, não tem equivalente, é o que tem dignidade. $^{55}$

A relação entre a análise da dignidade da pessoa humana e a proporcionalidade, apresenta ideias controversas sobre a estrutura normativa da dignidade. Para Robert Alexi:

De acordo com o conceito absoluto, a garantia da dignidade humana é considerada como uma norma que tem precedência sobre todas as outras normas, em todos os casos. Isso implica a impossibilidade, por preclusão, de realizar o balanceamento. Isso, a seu turno significa que a cada intervenção sobre a dignidade humana resta con-

${ }_{53}$ GUERRA, Sidney; MERÇON, Gustavo. Direito constitucional aplicado à função legislativa. Rio de Janeiro: América Jurídica, 2002, p. 96.

${ }^{54}$ SARLET, Ingo Wolfgang. A eficácia da dignidade humana. P.78

${ }^{55}$ KANT, Imanuel. A metafísica dos Costumes. 
substanciada uma violação à dignidade. Mesmo justificada, torna-se impossível haver uma intervenção sobre a dignidade humana ${ }^{56}$

A dignidade humana e proporcionalidade se diferenciam quanto a intervenções do Estado. Em cada intervenção sobre a dignidade humana corresponde a uma violação à mesma, enquanto que na proporcionalidade, esta está ligada à distinção entre intervenções justificadas e injustificadas, entendendo que a intervenção proporcional é justificável e constitucional. É a concepção de absoluto e relativo. ${ }^{57}$

A análise das intervenções se faz necessária diante da necessidade de proteção da dignidade humana. A intervenção do Estado só ' poderá ser justificada se esta ocorrer para proteger a dignidade, para proteger a vida e a liberdade.

A sociedade atravessa uma crise de valores, podendo-se afirmar que os próprios valores estão passando por crise; tal situação traz a ideia de que os valores morais estariam "doentes" e, logo, correndo perigo de extinção. "Valores em crise", por sua vez, é uma expressão que expõe o fato de que os valores morais não desapareceram, mas estão mudando de interpretação. ${ }^{58}$ Com a crise dos valores morais a justiça também se enfraquece, e a dignidade humana é aviltada, escancarando-se as injustiças.

O princípio da dignidade humana, diante da crise dos valores morais, sociais e éticos, tem sido a garantia de justiça. O colapso social, a desigualdade e a perda de identidade social, a violência que nasce na perda dos sonhos e da esperança, ainda têm no princípio da dignidade humana o portal para a Justiça.

\section{CONCLUSÕES}

A justiça é a primeira virtude das instituições sociais, como a verdade o é dos sistemas de pensamento. A Justiça é um valor, e pode ser entendida como valor essencialmente humano e profundamente necessário para as realizações do convívio humano, pois nela mora a semente da igualdade. O vínculo essencial para a vida com liberdade e dignidade humana, se desenvolve entre o direito e os fatos sociais, sob a

\footnotetext{
${ }^{56}$ ALEXY, Robert. A dignidade humana e a análise da proporcionalidade. p. 13. "In" Dignidade humana, Direitos sociais e não-positivismo incluso.

${ }^{57}$ Ibidem, p. 14.

${ }^{58}$ CORTELA; LA TAILLE apud TREVISOL, Maria Tereza Ceron. A construção de valores na escola, 2004, p. 22.
} 
influência da vida social, que de forma dinâmica acrescenta a cada dia novos valores, e o ser humano tem a tutela de seus direitos, para viver uma vida digna. Os valores interiores correspondem à essência da pessoa humana, neles estão os sentimentos e o senso de justiça que a potencializa em conformidade com a escala de valores da sociedade em que vive. A justiça é a primeira virtude das instituições sociais, como a verdade o é dos sistemas de pensamento.

A ideia de justiça ser um princípio garantidor da felicidade pessoal, e este princípio ser garantido por meio da ordem social, é um novo conceito de justiça, que protege determinados interesses, ou seja, aqueles que são reconhecidos como dignos dessa proteção pela maioria dos subordinados a essa ordem.

A história da humanidade e de suas ideologias, assim como de suas tendências político-econômicas, tornou o Direito frágil, suscetível aos desmandos do poder político e econômico, deixando a Justiça fragilizada. A desigualdade social e o desrespeito aos valores pessoais e aos direitos personalíssimos tem violado a dignidade da pessoa humana, fazendo com que a dor da injustiça aflore.

A justiça é uma das noções mais prestigiadas do universo espiritual, e está longe de ser um valor exclusivamente revolucionário, ela está relacionada à felicidade pessoal. Direito e Justiça são conceitos diferentes que às vezes andam em sintonia, outras não. Nem sempre caminham juntos. O direito busca a justiça, tem nela a sua finalidade de existir e operar na vida social. O direito deve ser o meio, o veículo para a realização da justiça.

O Direito e a justiça precisam se aparelhar para fortalecimento do ordenamento jurídico, tendo como objetivo proteger a pessoa em suas garantias individuais, em sua liberdade e dignidade.

A justiça como equidade é uma teoria de justiça que generaliza e leva a um nível mais alto de abstração. A justiça é a primeira virtude das instituições sociais. Cada pessoa possui uma inviolabilidade fundada na justiça, portanto, numa sociedade justa as liberdades da cidadania são consideradas invioláveis, Eis a primazia da justiça.

A noção de justiça formal está vinculada à igualdade, como o substrato comum à concepção de justiça. A igualdade está fundamentada em valores, e, estabelece como regra de justiça, a igualdade formal, por entender que ser justo é tratar da mesma forma os seres que são iguais em certo ponto de vista, que possuem uma mesma característica, a única que se deve levar em conta na administração da justiça. 
As desigualdades sociais representam as diferenças de possibilidades: de vida digna, de ter voz e ser ouvido, de existência de preconceitos e segregação social, um grito sufocado por justiça, um constrangimento que faz rasgar a alma da pessoa que se sente injustiçada.

Liberdade e igualdade tem na linguagem política um significado positivo, e a justiça se realiza nesses valores. O princípio da dignidade humana protege a vida, a liberdade, todos os direitos personalíssimos, e protegerá direitos futuros, como alicerce do Direito. Está vigente, e pode ser reconhecido como uma teoria de justiça diante da sua importância para tutelar novos direitos, sendo, portanto, uma bandeira de justiça.

\section{REFÊRÊNCIAS}

ALEXY, Robert. Dignidade humana, direitos sociais e não-positivismo inclusivo. Florianópolis, SC: Qualis, 2015.

ANDORNO, Roberto. Bioética Y dignidad de la persona. Madrid: Tecnos, 2012.

ARISTÓTELES. Ética a Nicômaco. 3. ed. Tradução Edson Bini. Bauru, SP: Edipro, 2009.

BOBBIO, Norberto. Direito e Estado no pensamento de Emanuel Kant. São Paulo: Mandarim, 2000.

BOBBIO, Norberto. Igualdade e liberdade. Rio de Janeiro: Ediouro, 2002.

DENNIS LLOYD, Barom. A ideia de lei. São Paulo: Martins Fontes, 2000.

TREVISOL, Maria Tereza Ceron. A construção de valores na escola. 2004.

DWORKIN, Ronald. Levando os direitos a sério. São Paulo: Martins Fontes, 2002.

FELIPPE, Mário Sotelo. Razão jurídica e dignidade humana. São Paulo: Max Limonad, 1996.

FERMENTÃO, Cleide Aparecida Gomes Rodrigues. Direito a liberdade: por um paradigma de essencialidade que tutele o direito personalíssimo da liberdade. Curitiba, PR: Juruá, 2009. 
GUERRA, Sidney; MERÇON, Gustavo. Direito constitucional aplicado à função legislativa. Rio de Janeiro: América Jurídica, 2002

KANT, Imanuel. A metafísica dos Costumes.

KELSEN, Hans. O que é Justiça? a justiça, o direito e a política no espelho da ciência. São Paulo: Martins Fontes, 2001.

KELSEN, Hans. Teoria Geral do Direito e do Estado. São Paulo. Martins Fontes, 1998.

KELSEN, Hans. O problema da Justiça. São Paulo: Martins Fontes,1998.

KOLM, Serge-Christophe. Teorias modernas da justiça. São Paulo. Martins Fontes.2000.

PERELMAN, Chaim. Ética e Direito. São Paulo: Martins Fontes, 2000.

PILON, Almir José. Liberdade e justiça: uma introdução à filosofia do direito em Kant e Rawls. Porto Alegre: Sérgio Antonio Fabris, 2002.

RAWLS, John. Uma Teoria da Justiça. São Paulo: Martins Fontes, 2000.

RAWLS, John. Justiça como equidade: uma reformulação. São Paulo: Martins Fontes, 2003.

ROSSEAU. J. J. Discurso sobre a origem e os fundamentos da desigualdade entre os homens. São Paulo. Martins Fontes, 1999.

SANTOS, Maria Celeste Cordeiro Leite. Transplante de órgãos e eutanásia. São Paulo: Revista dos Tribunais, 2001

SARLET, Ingo Wolfgang. A eficácia dos Direitos constitucionais. Porto Alegre: Livraria do Advogado, 2009.

VOLTAIRE. O preço da justiça. São Paulo: Martins Fontes, 2001. 